\title{
DESAIN ELEMEN STRUKTUR BALOK DAN KOLOM BETON BERTULANG PADA BANGUNAN BERTINGKAT MENGGUNAKAN SISTEM RANGKA PEMIKUL MOMEN KHUSUS (SRPMK)
}

\author{
(Design Of Structural Elements Of Reinforced Concrete Beams And Columns In Multi-Storey Buildings \\ Using A Special Moment Resisting Frame System (SMRFS)) \\ Cece Suhendi ${ }^{1}$, M.Rifki Ilyas ${ }^{2}$, Bambang Jatmika ${ }^{3}$, Richa Rahmaliya ${ }^{4}$ \\ 1,2,3,4 Universitas Nusa Putra \\ Korespondensi Penulis : Kab. Sukabumi \\ E-mail: cecesuhendi@nusaputra.ac.id, rifkinoordin@gmail.com, bamabangjatmika@nusaputra.ac.id, \\ richa.rahmaliya@nusaputra.ac.id
}

\begin{abstract}
ABSTRAK
Wilayah Indonesia merupakan salah satu wilayah yang sangat berpotensi terjadi bencana alam mengingat beberapa daerahnya terlewati oleh sesar baribis. Dengan demikian sudah sangat jelas bahwa wilayah tersebut memiliki massa bencana yang cukup banyak, yang menyebabkan dalam pembangunan infrastruktur harus benarbenar memperhatikan tingkat daktilitas suatu struktur. Pada skripsi ini akan mengkaji terkait desain balok dan kolom menggunakan SRPMK pada bangunan gedung bertingkat yang berfungsi sebagai rumah sakit yang berada di daerah karawang dan akan di perhitungkan berdasarkan SNI 2847 : 2013,SNI 1726 : $2012,1727: 2013$ serta SNI 2052 : 2017 dan akan dianalisis dengan dua kategori situs tanah yaitu tanah keras dan tanah lunak guna mengetahui reaksi struktur dan ragam tulangan dari kedua jenis situs tersebut. Pembebanan yang digunakan adalah beban mati,beban hidup dan beban gempa, untuk beban gempa menggunakan analisis respon spectrum, dari data-data tersebut akan dilakukan analisis menggunakan software analisa struktur dan selanjutnya hasil dari analisa struktur tersebut dapat menjadi modal awal dalam memperhitungkan ragam tulangan yang dibutuhkan serta dapat terverivikasinya perbedaan bangunan gedung yang di rancang di situs tanah keras dan tanah lunak. Dalam analisa struktur pada tanah keras dan tanah lunak memiliki persamaan dengan dimensi yang direncanakan yaitu dengan ukuran balok I 400x600 mm,balok II 500x300 mm, K1 700x700 mm, K2 650x650 mm dan K3 550x550 mm, namun memiliki perbedaan pada diameter dan jumlah tulangan yang dibutuhkan, untuk tanah keras dibutuhkan tulangan longitudinal 20D19,9D16,12D25,20D22 dan tulangan tanversal yaitu D10,D13 dan D16 sedangkan pada pada tanah keras dibutuhkan tulangan longitudinal 39D22,10D19,12D25,4D29 dan tulangan tanversal yaitu D13,D16 dan D19, dengan demikian jumlah serta dimensi tulangan tanah keras lebih kecil dari pada tanah lunak.
\end{abstract}

Kata kunci: Daktilitas,SRPMK,Tanah Keras,Tanah Lunak,Respon Spektrum.

\begin{abstract}
The territory of Indonesia is one of the areas that has the potential for natural disasters, considering that several areas have been crossed by baribis faults. Thus, it is very clear that the area has a large number of disasters, which causes infrastructure development to pay close attention to the ductility of a structure. This thesis will examine the beam and column design using SMRFS in a multi-storey building that functions as a hospital in the Karawang area and will be calculated based on SNI 2847: 2013, SNI 1726: 2012, 1727: 2013 and SNI 2052: 2017 and will be analyzed by two categories of soil sites, namely hard soil and soft soil in order to determine the structural reaction and the variety of reinforcement of the two types of sites. The loads used are dead load, live load and earthquake load, for earthquake loads using response spectrum analysis, from these data will be analyzed using structural analysis software and then the results of the structural analysis can be the initial capital in calculating the variety of reinforcement needed and can verify differences in buildings designed on hard and soft soil sites. In the analysis of the structure on hard soil and soft soil, it has similarities with the planned dimensions, namely the size of beam I $400 x 600 \mathrm{~mm}$, beam II $500 x 300 \mathrm{~mm}$, K1 $700 x 700 \mathrm{~mm}$, K2 $650 x 650 \mathrm{~mm}$ and K3 $550 x 550 \mathrm{~mm}$, but have differences in the diameter and amount of reinforcement required, for hard soil, longitudinal reinforcement is needed 20D19,9D16,12D25,20D22 and tanversal reinforcement, namely D10, D13 and D16, while in hard soil longitudinal reinforcement is needed 39D22,10D19,12D25 and tanversal reinforcement namely D13, D16 and D19, thus the number and dimensions of hard soil reinforcement are smaller than soft soil.
\end{abstract}

Keywords: Ductility, SMRFS, Hard Soil, Soft Soil, Response Spectrum. 


\section{PENDAHULUAN}

Menurut Badan Meteorologi Klimatologi dan Geofisika keaktifan gempabumi di Indonesia sangat tinggi, rata-rata setiap bulannya tercatat $400 \mathrm{kali}$, dalam periode 1991 sampai dengan 2007, tercatat $24 \mathrm{kali}$ gempabumi besar, di antaranya kejadian gempa bumi Aceh 26 Desember 2004 dengan kekuatan 9.3 SR, gempa bumi ini diikuti oleh tsunami besar yang menimbulkan korban ratusan ribu jiwa dan menimbulkan kerugian harta benda trilyunan rupiah serta gempa bumi Yogyakarta 26 Mei 2006 yang menimbulkan kerusakan infrastruktur yang sangat parah, dari uraian yang telah disampaikan di atas dapat kita ketahui betapa besarnya resiko bencana gempa yang terjadi di Indonesia.

Sebagian besar kota dan kabupaten di Jawa Barat, terutama wilayah di bagian selatan, dinyatakan berkategori rawan gempa dan longsor aktif, hal itu dikarenakan terdapat patahan-patahan aktif di bagian selatan Pulau Jawa, patahan yang terkenal melanda Indonesia akhir-akhiri ini bernama sesar baribis, sesar baribis merupakan sesar aktif yang membentang dari Subang, Sumedang, hingga Kuningan. ahli geodesi Australia, Achraff Koulali kemudian melakukan riset dan menemukan bahwa Sesar Baribis memanjang ke arah barat Subang melintasi Purwakarta, Karawang, Cibatu (Bekasi), Tangerang, sampai Rangkasbitung.

Dalam perencanaan struktur bangunan gedung ini adalah sebuah bangunan rumah sakit, bangunan ini akan di desain menggunakan SRPMK, seperti yang kita ketahui salah satu struktur yang sangat vital dalam menerima beban adalah balok dan kolom tentunya pada perencanaan balok dan kolom untuk ukuranya sangat beragam dan juga balok ndan kolom merupakan komponen struktur yang harus benar-benar diperhitungkan dalam desain bangunan gedung menggunakan SRPMK.

Salah satu dari syarat perhitungan SRPMK yaitu harus menentukan jenis situs tanah yang akan dibangun pada bangunan gedung, maka pada penelitian ini akan dikaji 2 jenis situs tanah yang akan di analisis yaitu tanah keras dan tanah lunak guna untuk mengetahui perbedaan perilaku kedua jenis struktur dan ragam penulangan balok dan kolom beton bertulang yang dibangun pada kedua jenis situs tanah tersebut.

\section{METODE PENELITIAN}

Metode penelitian ini menggunakan metode kualitatif dimana dalam penelitiannya mengacu pada litelatur-litelatur serta peraturan pemerintah yaitu SNI dalam desain komponen struktur utama yaitu balok dan kolom, dalam analisis ini akan menjelaskan berkaitan dengan desain bangunan gedung rumah sakit yang berada didaerah Karawang Jawa Barat menggunakan SRPMK (Sistem Rangka Pemikul Momen Khusus), yang mana pada kesempatan penelitian kali ini akan dikaji terkait perbedaan kedua situs tanah yaitu tanah keras dan tanah lunak guna untuk mengetahui perbedaan prilaku struktur serta ragam penulangan antara situs tanah keras dan tanah lunak.

Untuk referensi dalam mendesain bangunan gedung ini peneliti mengacu kepada peraturan-peraturan yang telah ditetapkan pemerintah dalam mendesain bangunan gedung tahan gempa agar terciptanya keselarasan dalam mendesain antara perencana dan peraturan yang telah ditetapkan adapun dalam perencanaan bangunan ini digunakan peraturan pemerintah berupa SNI 2847 : 2013 tentang persyaratan beton structural untuk bangunan gedung, SNI $1726: 2012$ tentang tentang tatacara perencanaan tahan gempa untuk struktur bangunan gedung dan non gedung, SNI 1727 : 2013 dan SNI 2052 : 2017 tentang mutu baja tulangan beton serta juga dalam perhitungannya penulis mengacu kepada beberapa literature terpercaya seperti halnya dalam analisis hitungan tulanagn

Dalam desain bangunan gedung rumah sakit ini diperlukan data-data pendukung seperti data primer dan data sekunder,guna untuk mendukung terkait penelitian yang sedang dianalisis adapun data primer yang dibutuhkan dalam penelitian ini adalah sebagai berikut :

1. Data Gambar Perencanaan Bangunan Gedung

2. Data Lokasi Bangunan Gedung Tersebut dibangun

Adapun data sekunder yang dibutuhkan adalah data pembebanan sebagai acuan agar struktur yang dianalisis dapat menerima beban rencana yang diperlukan berikut data pembebanan yang diperlukan :

1. Beban Hidup Bangunan Gedung

2. Beban Mati Bangunan Gedung

3. Beban Gempa Bangunan Gedung.

Pada anlisis beban hidup,mati dan gempa penulis mengacu pada SNI SNI 1726:2012 tentang tatacara perencanaan ketahanan gempa untuk struktur bangunan gedung dan non gedung. Untuk analisis beban gempa yang digunakan adalah analisis beban gempa respon spectrum yang perhitungannya bisa dilakukan dengan 
cara melihat SNI dan situs puskim yang tersedia di layanan internet, pada penelitian ini akan di teliti analisis respon spectrum pada dua kondisi situs tanah yaitu tanah keras dan tanah lunak. Berikut bagan alir penelitian yang dilakukan pada bangunan gedung rumah sakit yang akan dianalisis yakni balok dan kolom pada kedua jenis situs tanah yaitu keras dan lunak seperti pada Gambar 1.

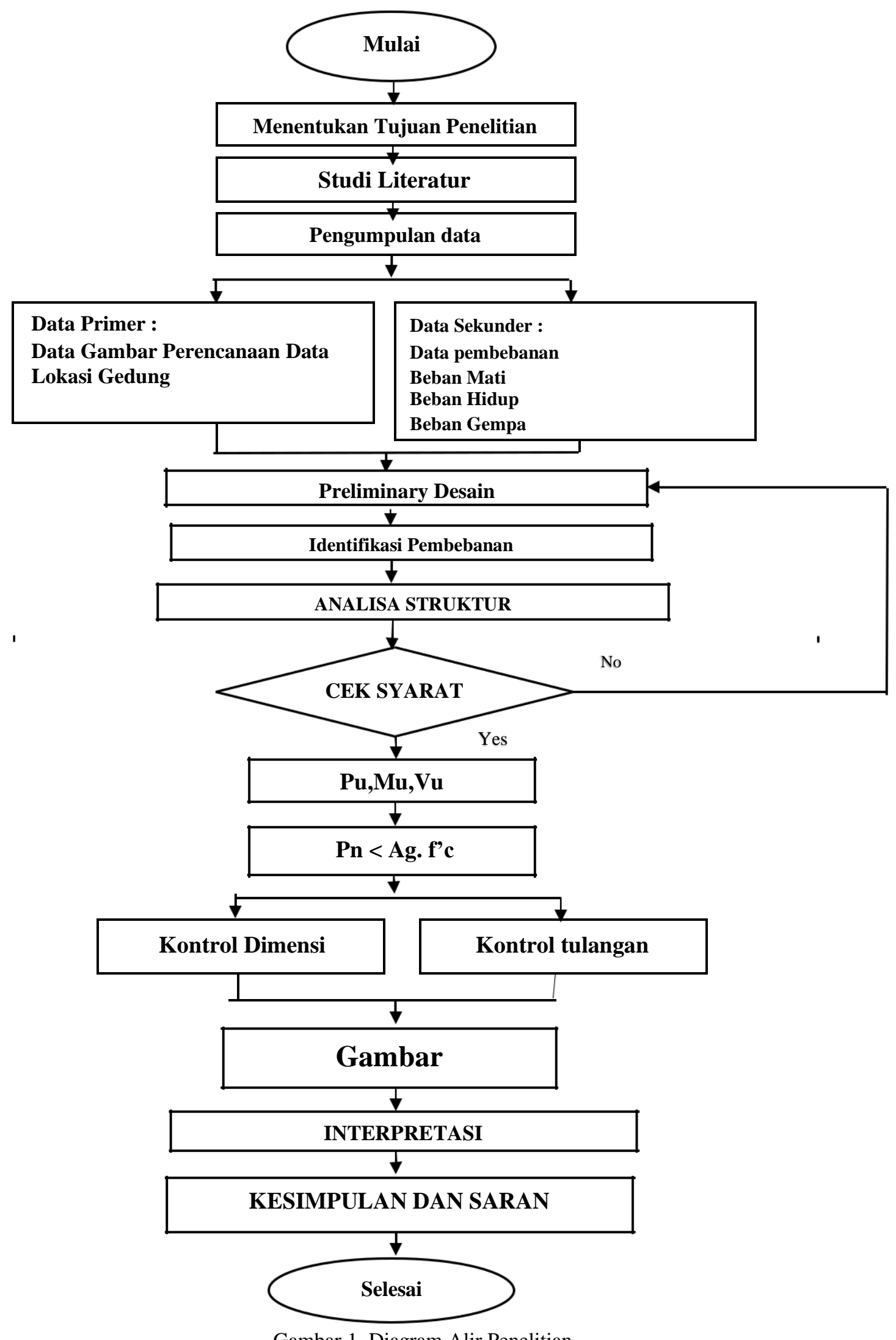

Gambar 1. Diagram Alir Penelitian 


\section{Data Aanlisis Bnagunan Gedung}

\section{HASIL DAN PEMBAHASAN}

Dalam merencanakan desain balok dan kolom suatu komponen struktur bangunan gedung maka dengan ini diperoleh data perencanaan bangunan gedung yang akan dianalisis berupa bangunan gedung rumah sakit yang berlokasi di daerah Karawang Jawa Barat untuk material yang digunakan adalah beton bertulang dengan mutu beton adalah $30 \mathrm{MPa}$ dan mutu baja tulangan adalah BJTS 57, adapun untuk komponen struktur lentur balok yang didesain adalah $400 \times 600 \mathrm{~mm}, 300 \times 500 \mathrm{~mm}$ dan untuk kolom 700 x $700 \mathrm{~mm}, 650 \times 650$ $\mathrm{mm}$ dan $550 \times 550 \mathrm{~mm}$.

\section{Pembebanan Pada Struktur}

Dari data diatas dapat kita gunakan sebagai mpdal awal dalam memberikan preliminary desain terhadap beban-beban yang akan didistribusikan terhadap software analisa struktur yang mana beban yang akan di perhitungkan pada penelitian kali ini meliputi beban mati,hidup dan gempa berikut daftar rincian pembebanan yang mengacu pada SNI 1727 :2013 dan PPUG 1983 pada bangunan gedung rumah sakit :

Tabel 1 Data Analisis Beban Mati

\begin{tabular}{llll}
\hline \multicolumn{5}{c}{ Data Beban Mati } \\
\hline Nama Beban Mati & Berat & Nama Beban Mati & Berat \\
\hline Beban Plat Lt 1-7 & & Berat Water Proofing & $5 \mathrm{~kg} / \mathrm{m} 2$ \\
\hline Berat Plester $(2,5 \mathrm{~cm})$ & Berat Plafon & Berat Mechanical Elecktrical & $25 \mathrm{~kg} / \mathrm{m} 2$ \\
\hline Berat Mechanical Elecktrical & $25 \mathrm{~kg} / \mathrm{m} 2$ & Berat Plafon & $18 \mathrm{~kg} / \mathrm{m} 2$ \\
\hline Berat Plafon & $18 \mathrm{~kg} / \mathrm{m} 2$ & Beban Pada Balok & \\
\hline Berat Kramik & $24 \mathrm{~kg} / \mathrm{m} 2$ & Berat dinding $1 / 2$ bata & $825 \mathrm{~kg} / \mathrm{m} 2$ \\
\hline Beban Plat Lt Atap & & Berat dinding bata ringan & $330 \mathrm{~kg} / \mathrm{m} 2$ \\
\hline Berat plester $(2,5 \mathrm{~cm})$ & $53 \mathrm{~kg} / \mathrm{m} 2$ & Berat dinding partisi gypsum & $50 \mathrm{~kg} / \mathrm{m} 2$ \\
\hline
\end{tabular}

Adapun beban hidup yang akan diperhitungkan dalam mendesain bangunan gedung ini disesuaikan dengan fungsi dari bangunan gedung ini berupa rumah sakit umum yang mana dalam pembebanannya mengacu pada SNI 1727 dan PPUG 1983 berikut rincian beban hidup pada bangunan gedung rumah sakit :

Tabel 2 Data Analisis Beban Hidup

\begin{tabular}{llll}
\hline \multicolumn{4}{c}{ Data Beban Hidup } \\
\hline Nama Beban Hidup & Berat & Nama Beban Hidup & Berat \\
\hline Lantai ruang klinik,igd dan oprasi & $287 \mathrm{~kg} / \mathrm{m} 2$ & Ruang pasien & $192 \mathrm{~kg} / \mathrm{m} 2$ \\
\hline Ruang igd & $287 \mathrm{~kg} / \mathrm{m} 2$ & Ruang rapat dan kantor & $400 \mathrm{~kg} / \mathrm{m} 2$ \\
\hline Klinik & $287 \mathrm{~kg} / \mathrm{m} 2$ & Auditorium & $350 \mathrm{~kg} / \mathrm{m} 2$ \\
\hline Ruang oprasi & $287 \mathrm{~kg} / \mathrm{m} 2$ & lantai atap & $100 \mathrm{~kg} / \mathrm{m} 2$ \\
\hline Ruang laboratorium dan ruang bayi & $287 \mathrm{~kg} / \mathrm{m} 2$ & Bordes & $300 \mathrm{~kg} / \mathrm{m} 2$ \\
\hline & & Koridor & $300 \mathrm{~kg} / \mathrm{m} 2$ \\
\hline
\end{tabular}

Untuk perencanaan pembebanan gempa mengacu terhadap SNI 1726 : 2012 terkait tentang tatacara perencanaan ketahanan gempa untuk struktur bangunan gedung dan non gedung, pada analisis bangunan gedung ini akan digunakan analisis beban gempa respon spectrum dengan mengkaji dua klasifikasi situs tanah yang berbeda yaitu tanah keras dan tanah lunak berikut hasil perhitungan beban gempa analisis respon spectrum di daerah Karawang provinsi Jawa Barat dengan dua kategori situs tanah yang berbeda :

Tabel 3 Data Analisis Beban Gempa Respon Spektrum

\begin{tabular}{llll}
\hline & \multicolumn{2}{c}{ Data Beban Gempa } \\
\hline Tanah Keras & Nilai & Tanah Lunak & Nilai \\
\hline Ss & $0.681 \mathrm{~g}$ & Ss & $0.681 \mathrm{~g}$ \\
\hline S1 & $0.289 \mathrm{~g}$ & S1 & $0.289 \mathrm{~g}$ \\
\hline Fa & $1.128 \mathrm{~g}$ & Fa & $1.338 \mathrm{~g}$ \\
\hline Fv & $1.511 \mathrm{~g}$ & FV & $2.845 \mathrm{~g}$ \\
\hline SMS & $0.770 \mathrm{~g}$ & SMS & $0.911 \mathrm{~g}$ \\
\hline SM1 & $0.436 \mathrm{~g}$ & SM1 & $0.822 \mathrm{~g}$ \\
\hline SDS & $0.513 \mathrm{~g}$ & SDS & $0.607 \mathrm{~g}$ \\
\hline
\end{tabular}




\begin{tabular}{llll}
\hline SD1 & $0.291 \mathrm{~g}$ & SD1 & $0.548 \mathrm{~g}$ \\
\hline T0 & $0.113 \mathrm{~g}$ & T0 & $0.180 \mathrm{~g}$ \\
\hline TS & $0.568 \mathrm{~g}$ & TS & $0.902 \mathrm{~g}$ \\
\hline
\end{tabular}

Dari hasil perhitungan beban gempa respon spectrum dengan mengkaji dua klasifikasi situs tanah didapatkan diagram tanah keras dan tanah lunak sebagai berikut :

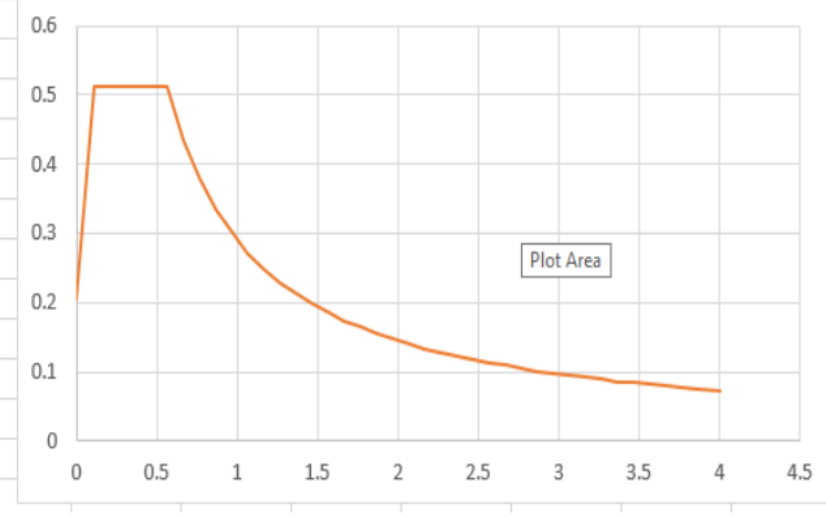

a

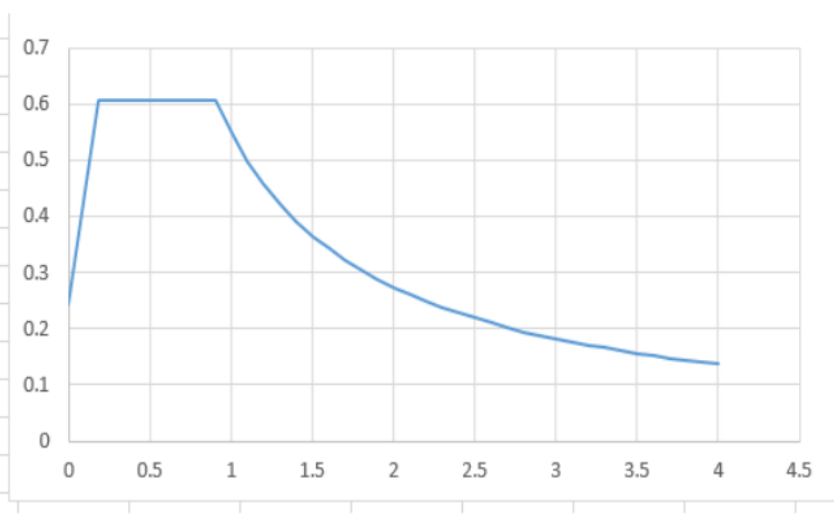

b

Gambar 2. (a) respon spectrum tanah keras,(b) respon spectrum tanah lunak

Kombinasi pembebanan yang dugunakan sesuai SNI $1727: 2013$ sebagai berikut :

1. $1,4 \mathrm{D}$

2. $1,2 \mathrm{DL}+1,6 \mathrm{LL}$

3. $1,2 \mathrm{DL}+1,0 \mathrm{LL}+1,0 \mathrm{EX}+0,3 \mathrm{EY}$

4. $1,2 \mathrm{DL}+1,0 \mathrm{LL}+0,3 \mathrm{EX}+1,0 \mathrm{EY}$;

Analisis perhitungan gaya-gaya dalam seperti gaya aksial,geser dan momen dilakukan pada satu buah bangunan gedung, dengan dua situs tanah yaitu tanah keras dan tanah lunak. Dari hasil analisis perhitungan gaya-gaya dalam tersebut menjadi modal awal dalam penentuan ragam tulangan, serta perbedaan yang menghasilkan bahwasanya ketika kondisi suatu tanah semakin lunak maka akan semakin besar beban lateral yang diterimanya ini terbukti dari ragam penulangan bangunan gedung yang dianalisis dengan dua kategori situs tulangan tanah lunak lebih besar dari pada tulangan tanah keras berikut hasil output analisis struktur :

\section{Desain Penulangan Elemen Struktur Tanah Keras}

\section{Balok}

Balok 400 x $600 \mathrm{~mm}$,Mu tumpuan atas balok sebesar 205,1559 kN-m dengan diameter tulangan longitudinal 6D19, Mu tumpuan bawah balok sebesar 102,5779 kN-m dengan diameter tulangan longitudinal 4D16, Mu tumpuan bentang atas balok sebesar $131,1061 \mathrm{kN}-\mathrm{m}$ dengan diameter tulangan longitudinal 4D19, Mu tumpuan bentang bawah balok sebesar $51,2889 \mathrm{kN}$-m dengan diameter tulangan longitudinal 3D19, adapun untuk tulangan transversal di dalam zona sendi plastis sepanjang $1200 \mathrm{~mm}$ dengan $\mathrm{Vu}=220 \mathrm{kN}-\mathrm{m}$ dengan 2 kaki D13 @ 100 mm, tulangan tanserval di luar zona sendi plastis Vu=174,4 kN-m dengan 2 kaki D10 @ $130 \mathrm{~mm}$. Balok $300 \times 500 \mathrm{Mu}$ tumpuan atas balok sebesar $153.7081 \mathrm{kN}-\mathrm{m}$ dengan diameter tulangan longitudinal 4D19, Mu tumpuan bawah balok sebesar 76,854 kN-m dengan diameter tulangan longitudinal 3D16, Mu tumpuan bentang atas balok sebesar $128.771 \mathrm{kN}-\mathrm{m}$ dengan diameter tulangan longitudinal 3D19, $\mathrm{Mu}$ tumpuan bentang bawah balok sebesar 64,385 kN-m dengan diameter tulangan longitudinal 2D16, adapun untuk tulangan transversal di dalam zona sendi plastis $\mathrm{Vu}=95,636 \mathrm{kN}-\mathrm{m}$ dengan 2 kaki D10 @ 200 mm, tulangan tanserval di luar zona sendi plastis Vu=95,636 kN-m dengan 2 kaki D10 @ 200 mm.

\section{Kolom}

Kolom $700 \times 700$ desain tulangan longitudinal kolom $700 \times 700$ dengan $\mathrm{Pu}=4784,773 \mathrm{kN}$-m diperoleh tulangan longitudinal 12D25, kuat kolom telah terpenuhi dimana $\sum \geq \sum$, desain tulangan tanversal kolom $700 \times 700$ dengan $\mathrm{Ve}=190,322 \mathrm{kN}-\mathrm{m}$ diperoleh tulangan tanversal 4 kaki D16 didalam zona sendi plastis sepanjang $700 \mathrm{~mm} @ 100 \mathrm{~mm}$ dan diluar zona sendi plastis @ $150 \mathrm{~mm}$, Hubungan Balok Kolom (HBK) telah terpenuhi sebab memenuhi rumus berikut $\emptyset>\mathrm{Vu}=\mathrm{Vj}=\mathrm{Vsway}-\mathrm{T} 1-\mathrm{C} 2(3721,6 \mathrm{kN}>1604,84$ $\mathrm{kN}$ ), desain tulangan tanversal HBK $700 \times 700$ dan $400 \times 600$ adalah 4D16 @70 mm. Kolom $650 \times 650$ Desain tulangan longitudinal kolom 650 x 650 dengan $\mathrm{Pu}=2922,92 \mathrm{kN}$-m diperoleh tulangan longitudinal 
12D22, kuat kolom telah terpenuhi dimana $\sum \geq \sum$, desain tulangan tanversal kolom $650 \times 650$ dengan $\mathrm{Ve}=$ 190,322 kN-m diperoleh tulangan tanversal 4 kaki D13 didalam zona sendi plastis sepanjang 650 mm @ 110 mm dan diluar zona sendi plastis @ 140 mm, Hubungan Balok Kolom (HBK) telah terpenuhi sebab memenuhi rumus berikut $\varnothing>\mathrm{Vu}=\mathrm{Vj}=$ Vsway $-\mathrm{T} 1-\mathrm{C} 2(3147 \mathrm{kN}>1604,84 \mathrm{kN})$, desain tulangan tanversal HBK 650 x 650 dan 400 x 600 adalah 4D10@50 mm. Kolom 550 x 550 mm desain tulangan longitudinal kolom $550 \times 550$ dengan $\mathrm{Pu}=1708,378 \mathrm{kN}-\mathrm{m}$ diperoleh tulangan longitudinal 8D22, kuat kolom telah terpenuhi dimana $\sum \geq \sum$, desain tulangan tanversal kolom 550 x 550 dengan $\mathrm{Ve}=190,322 \mathrm{kN}$ m diperoleh tulangan tanversal 3 kaki D13 didalam zona sendi plastis sepanjang 600 mm @ $100 \mathrm{~mm}$ dan diluar zona sendi plastis @ $120 \mathrm{~mm}$, Hubungan Balok Kolom (HBK) telah terpenuhi sebab memenuhi rumus berikut $\varnothing>\mathrm{Vu}=\mathrm{Vj}=\mathrm{V}$ sway $-\mathrm{T} 1-\mathrm{C} 2(2252>1604,84 \mathrm{kN})$, desain tulangan tanversal HBK 550 х 550 dan 400 x 600 adalah 3D10 @50 mm.

\section{Desain Penulangan Elemen Struktur Tanah Lunak}

\section{Balok}

Balok 400 × $600 \mathrm{Mu}$ tumpuan atas balok sebesar 303,8927 kN-m dengan diameter tulangan longitudinal 6D22, Mu tumpuan bawah balok sebesar 151,9463 kN-m dengan diameter tulangan longitudinal 4D19, Mu tumpuan bentang atas balok sebesar $287,8124 \mathrm{kN}-\mathrm{m}$ dengan diameter tulangan longitudinal 5D22, $\mathrm{Mu}$ tumpuan bentang bawah balok sebesar $75,97317 \mathrm{kN}$-m dengan diameter tulangan longitudinal 3D19, adapun untuk tulangan transversal di dalam zona sendi plastis sepanjang $1200 \mathrm{~mm}$ dengan $\mathrm{Vu}=245 \mathrm{kN}-\mathrm{m}$ dengan 2 kaki D16 @ 100 mm, tulangan tanserval di luar zona sendi plastis Vu=199 kN-m dengan 2 kaki D13 @ 230 $\mathrm{mm}$, cut off points terjadi pada tulangan 4D22 sepanjang $2800 \mathrm{~mm}$. Balok 300 x $500 \mathrm{Mu}$ tumpuan atas balok sebesar 210,7369 kN-m dengan diameter tulangan longitudinal 4D22, Mu tumpuan bawah balok sebesar 105,3684 kN-m dengan diameter tulangan longitudinal 3D19, Mu tumpuan bentang atas balok sebesar $184,4902 \mathrm{kN}-\mathrm{m}$ dengan diameter tulangan longitudinal 4D22, Mu tumpuan bentang bawah balok sebesar $64,385 \mathrm{kN}-\mathrm{m}$ dengan diameter tulangan longitudinal 2D16, adapun untuk tulangan transversal di dalam zona sendi plastis Vu $=126,168 \mathrm{kN}$-m dengan 2 kaki D16 @ $100 \mathrm{~mm}$, tulangan tanserval di luar zona sendi plastis $\mathrm{Vu}=126,168$ kN-m dengan 2 kaki D16 @ 100 mm.

\section{Kolom}

Kolom 700 x 700 Desain tulangan longitudinal kolom 700 × 700 dengan $\mathrm{Pu}=4884.778 \mathrm{kN}$-m diperoleh tulangan longitudinal 8D25+2D29, kuat kolom telah terpenuhi dimana $\sum \geq \sum$, desain tulangan tanversal kolom 700 x 700 dengan $\mathrm{Ve}=200,322 \mathrm{kN}-\mathrm{m}$ diperoleh tulangan tanversal 4 kaki D19 didalam zona sendi plastis sepanjang $700 \mathrm{~mm} @ 100 \mathrm{~mm}$ dan diluar zona sendi plastis @ $150 \mathrm{~mm}$, Hubungan Balok Kolom (HBK) telah terpenuhi sebab memenuhi rumus berikut $\emptyset>\mathrm{Vu}=\mathrm{Vj}=$ Vsway -T1-C2 $(3721,6 \mathrm{kN}>$ 2152kN),desain tulangan tanversal HBK 700 x 700 dan 400 x 600 adalah 4D16 @70 mm. Kolom 650 x 650 Desain tulangan longitudinal kolom 650 × 650 dengan $\mathrm{Pu}=3022,82 \mathrm{kN}-\mathrm{m}$ diperoleh tulangan longitudinal $8 \mathrm{D} 22+2 \mathrm{D} 25$, kuat kolom telah terpenuhi dimana $\sum \geq \sum$, desain tulangan tanversal kolom 650 x 650 dengan $\mathrm{Ve}=200,322 \mathrm{kN}-\mathrm{m}$ diperoleh tulangan tanversal 4 kaki D16 didalam zona sendi plastis sepanjang 650

mm@110 mm dan diluar zona sendi plastis @ 140 mm, Hubungan Balok Kolom (HBK) telah terpenuhi sebab memenuhi rumus berikut $\varnothing>\mathrm{Vu}=\mathrm{Vj}=\mathrm{Vsway}-\mathrm{T} 1-\mathrm{C} 2(3147 \mathrm{kN}>1604,84 \mathrm{kN})$, desain tulangan tanversal HBK 650 x 650 dan 400 x 600 adalah 4D13@50 mm. Kolom 550 x 550 Desain tulangan longitudinal kolom 550 x 550 dengan $\mathrm{Pu}=1908,377 \mathrm{kN}-\mathrm{m}$ diperoleh tulangan longitudinal 12D22, kuat kolom telah terpenuhi dimana $\sum \geq \sum$, desain tulangan tanversal kolom 550 x 550 dengan $\mathrm{Ve}=200,322 \mathrm{kN}$ m diperoleh tulangan tanversal 4 kaki D13 didalam zona sendi plastis sepanjang $600 \mathrm{~mm} @ 100 \mathrm{~mm}$ dan diluar zona sendi plastis @ 120 mm, Hubungan BalokKolom (HBK) telah terpenuhi sebab memenuhi rumus berikut $\varnothing>\mathrm{Vu}=\mathrm{Vj}=\mathrm{V}$ sway $-\mathrm{T} 1-\mathrm{C} 2(2252>2152 \mathrm{kN})$, desain tulangan tanversal HBK $550 \times 550$ dan 400 x 600 adalah 4D10@50 mm.

Dengan analisis perhitungan tulangan struktur yang sama, anatara analisa perhitungan tulangan yang dilakukan pada situs tanah keras dan tanah lunak untuk mengetahui keperluan tulangan lentur didapatkan interpretasi gambar analisis balok dan kolom sebagai berikut :

\section{Kondisi Tanah Keras}

\section{Balok 400x600mm}
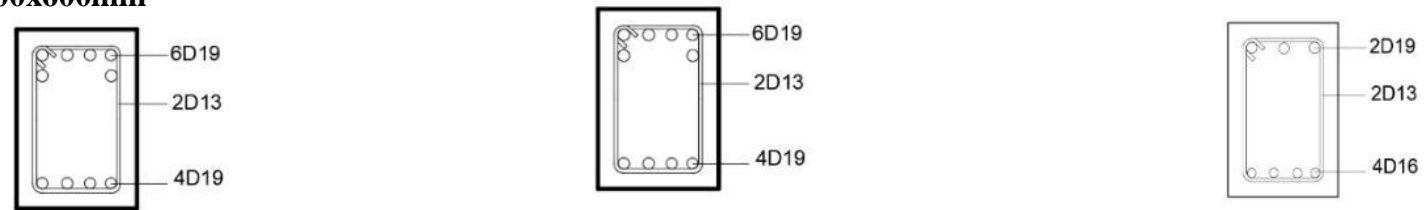

J-TESLINK @ 2020

https://teslink.nusaputra.ac.id 


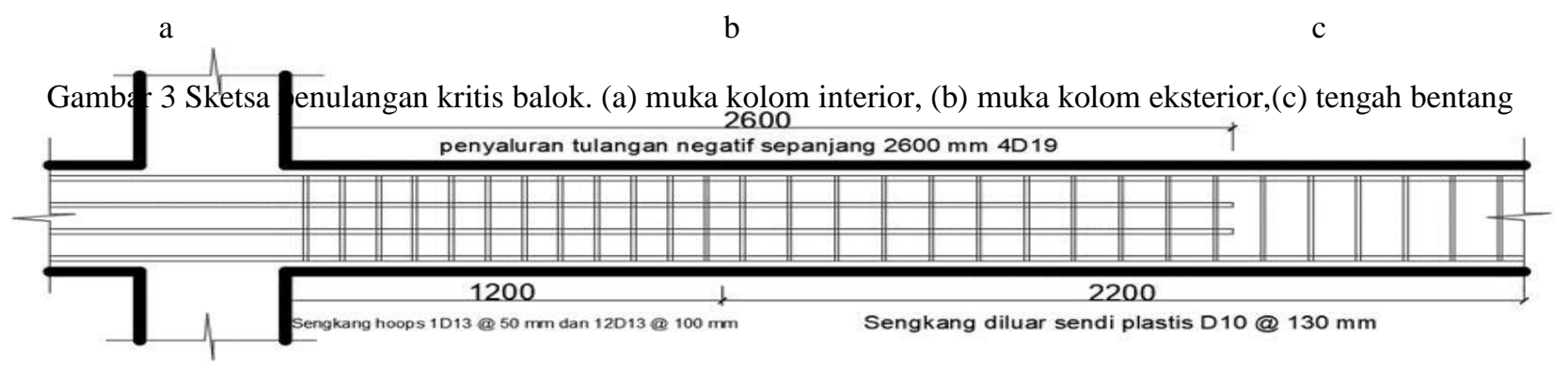

\section{Balok 300x500mm}

Gambar 4. detailing tulangan tanserval 400 x600

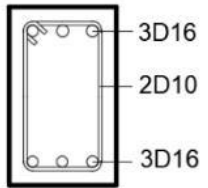

a

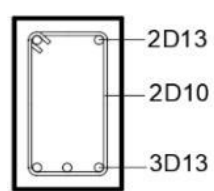

b

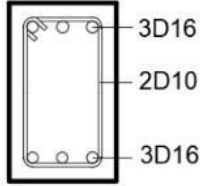

c

Gambar 5 Sketsa penulangan kritis balok 300x500. (a) muka kolom interior, (b) tengah bentang,(c) muka

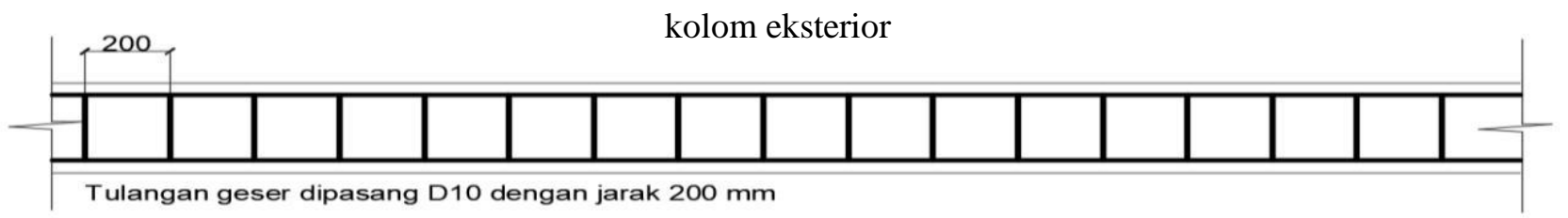

Gambar 6 Detailing penulangan geser pada balok 300 x 500

\section{Kolom}
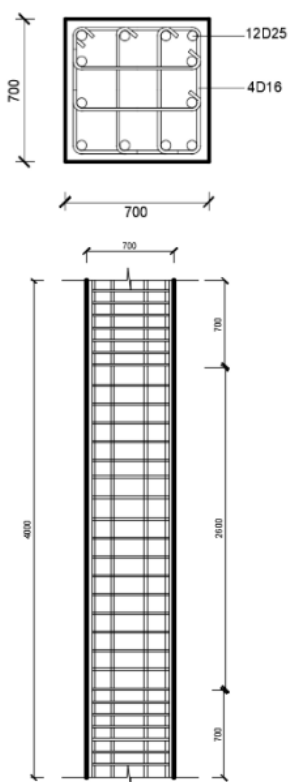

a
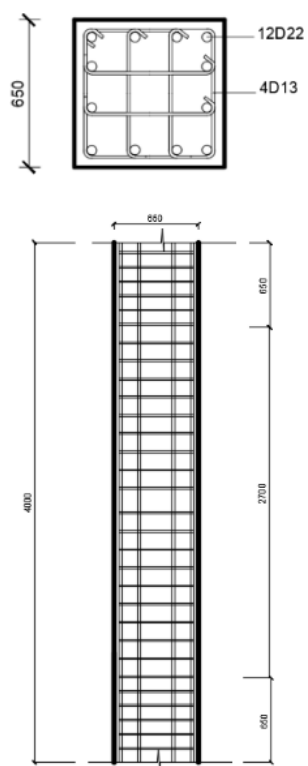

b
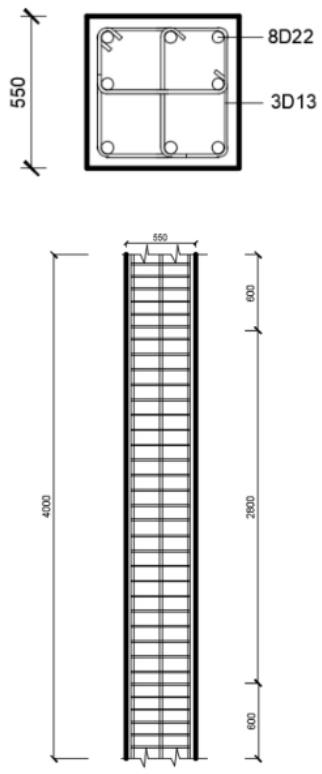

$\mathrm{c}$

Gambar 7 Desain tulangan tekan dan geser (a) Kolom 700 x 700, (b) 650 x 650, (c) 550 x 550 SRPMK

\section{Kondisi Tanah Lunak}

\section{Balok 400x600mm}

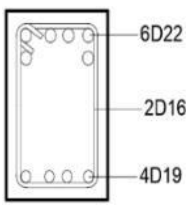

a

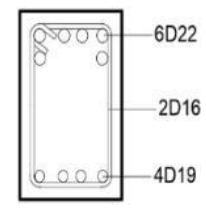

b c J-TESLINK @ 2020

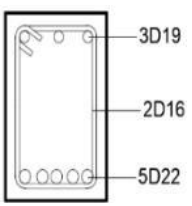

$5 \mathrm{D} 22$ 
Gambar 8 Sketsa penulangan kritis balok. (a) muka kolom interior, (b) muka kolom eksterior,(c) tengah bentang

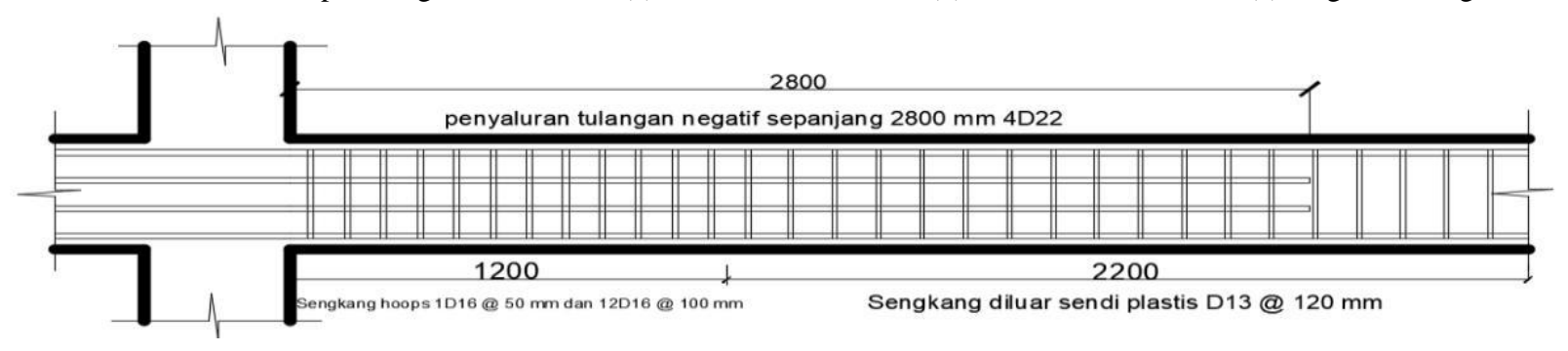

Gambar 8. detailing tulangan tanserval 400 x600

\section{Balok 300x500mm}
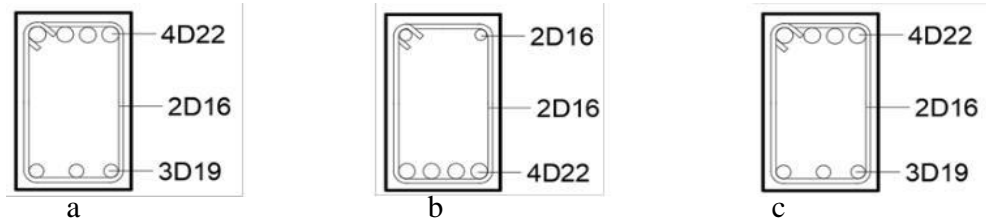

Gambar 9 Sketsa penulangan kritis balok 300x500. (a) muka kolom interior, (b) tengah bentang,(c) muka kolom eksterior

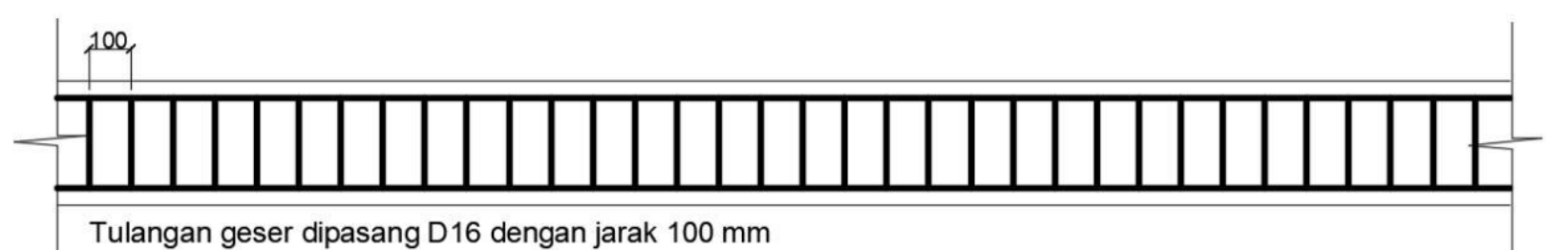

Gambar 10 Detailing penulangan geser pada balok 300 x 500
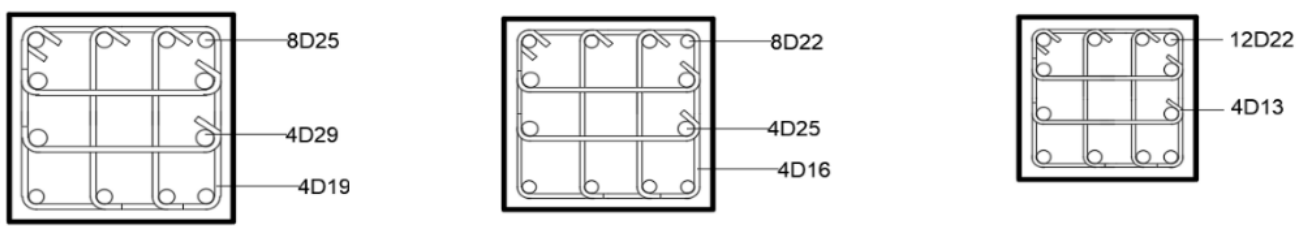

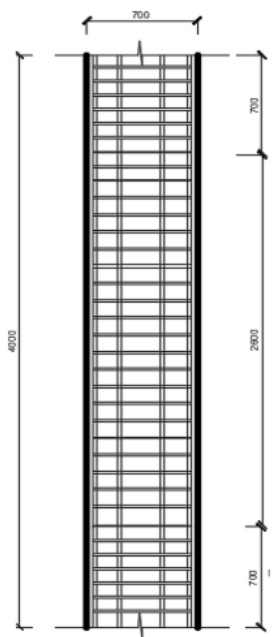

a

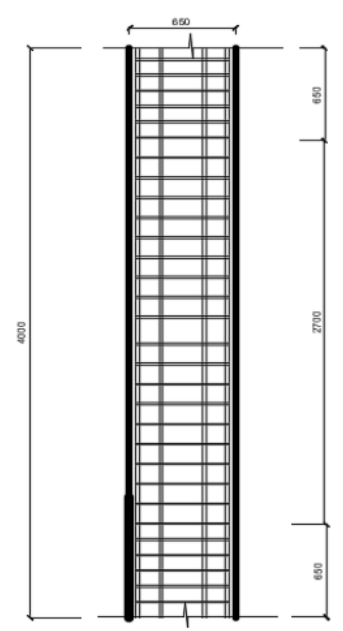

$\mathrm{b}$

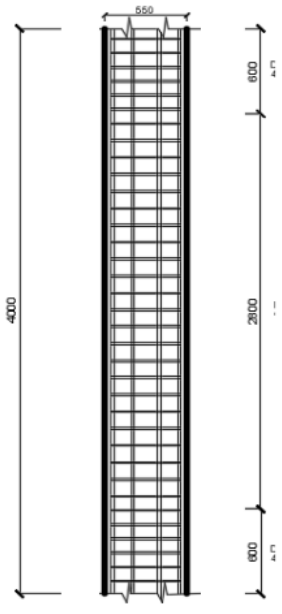

$\mathrm{c}$

Gambar 7 Desain tulangan tekan dan geser (a) Kolom 700 x 700, (b) 650 x 650, (c) 550 x 550 SRPMK KESIMPULAN

Berdasarkan hasil penelitian pada bangunan gedung rumah sakit yang di desain menggunakan Sistem Rangka Pemikul Momen Khusus (SRPMK) yang mengkaji dua kategori situs tanah yaitu tanah keras dan tanah lunak didapatkan kesimpulan sebagai berikut :

1. Dalam analisa struktur tanah keras dan tanah lunak memiliki persamaan dengan dimensi yang direncanakan yaitu dengan ukuran balok I 400x600 mm,balok II 500x300 mm, K1 700x700 mm, K2 650x650 mm dan 
K3 550x550 mm, namun memiliki perbedaan pada diameter dan jumlah tulangan yang dibutuhkan, untuk tanah keras dibutuhkan tulangan longitudinal 20D19,9D16,12D25,20D22 dan tulangan tanversal yaitu D10,D13 dan D16 sedangkan pada pada tanah keras dibutuhkan tulangan longitudinal 39D22,10D19,12D25,4D29 dan tulangan tanversal yaitu D13,D16 dan D19. Dengan demikian jumlah serta dimensi tulangan tanah keras lebih kecil dari pada tanah lunak.

2. Ragam tulangan untuk tanah keras balok 400x600 mm didapatkan tulangan longitudinal 6D19, 4D16, 4D19, 3D19, untuk tulangan tanversal didapatkan 2 kaki D13 dan 2 kaki D10, balok 500x300 mm didapatkan tulangan longitudinal 4D19, 3D16, 3D19, 2D16, kolom $700 \times 700 \mathrm{~mm}$ tualangan longitudinal 12D25 diperoleh tulangan tanversal 4 kaki D16,kolom 650x650 mm tulangan longitudinal 12D22 diperoleh tulangan tanversal 4 kaki D13, kolom 550x550 mm tulangan longitudinal 8D22 diperoleh tulangan tanversal 3 kaki D13. Ragam tulangan untuk tanah lunak balok 400x600 mm didapatkan tulangan longitudinal 6D22, 4D19, 5D22, 3D1, untuk tulangan tanversal 2 kaki D16 dan 2 kaki D1, 500x300 didapatkan tulangan longitudinal 4D22, 3D19, 4D22, 2D16 untuk tulangan transversal 2 kaki D16 dan 2 kaki D16, kolom 700x700 mm tualangan longitudinal 8D25+4D29 diperoleh tulangan tanversal 4 kaki D19,kolom 650x650 mm tulangan longitudinal 8D22+4D25 diperoleh tulangan tanversal 4 kaki D16, kolom 550x550 mm tulangan longitudinal 12D22 diperoleh tulangan tanversal 4 kaki D13.

\section{DAFTAR PUSTAKA}

Aidhil Ridho.2018” Studi Komparasi Detailing Desain Komponen Lentur Struktur Beton Bertulang SRPMK Dan SRPMM".(Jurnal) Padang : Universitas Dharma Andalas

Ansyori Rusdi.2017.”Desain Elemen Struktuur Atasa dengan Sistem Ganda SRPMK dan SDSK”(Skripsi) Padang: Universitas Abdalas

Badan Standarisasi Nasional. 2012. "Tata Cara Perencanaan Ketahanan Gempa Untuk Struktur Bangunan Gedung dan Non Gedung, SNI 1726:2012”. Jakarta : BSN

Badan Standarisasi Nasional. 2013. "Persyaratan beton struktural untuk bangunan gedung, SNI 2847:2013". Jakarta: BSN

Badan Standarisasi Nasional. 2013. "Beban minimum untuk perencanaan bangunan gedung dan struktur lain, SNI 1727:2013 “. Jakarta: BSN

Canonica Lucio. 2012 “'Memahami Mekanika Teknik". Jakarta : Penerbit Airlangga

Dhini Angelina,2019"Analisis dan Desain Elemen Struktur Beton Bertulang pada Gedung yang Mhemiliki Kolom Miring dengan SRPMB"(Skripsi) Lampung : Universitas Negeri Lampung

Fitriyani lailatul dan warsito,2019" Studi Perencanaan Struktur Beton Bertulang Dengan Sistem Rangka Pemikul Momen Khusus (Srpmk) Tahan Gempa Pada Ijen Suites Hotel Kota Malang” (Jurnal)Malang :Universitas Islam Malang

Imran, Iswandi dan Fajar Hendrik. 2014. "Perencanaan Lanjut Struktur Beton Bertulang". Bandung: Penerbit ITB Imran,Iswandi dan Ediansjah Zulkifli.2014.'’Perencanaan dasar beton bertulang'. Bandung: Penerbit ITB

Izzah, Nurul. 2017. " Disain Elemen Struktur Bangunan Bertingkat dengan Sistem Rangka Pemikul Momen Khusus (SRPMK)". Padang : Universitas Andalas

Novita Rahmah.2019 "Perencanaan Konstruksi Beton Bertulang Gedung Hotel 5 Lantai Dan Rooftop Dengan Sistem Rangka Pemikul Momen Khusus (Srpmk) Di Surakarta”(Skripsi) Surakarta : Universitas Muhammadiyah Surakarta

Pamungkas, Anugrah dan Harianty Erni.2012 "struktur beton bertulang tahan gempa". Yogyakarta: Penerbit Andi Rahmad Budi dkk.2019 "Analisis Pengaruh Faktor Modifikasi Respon, Srpmk Struktur Gedung Beton Bertulang Pada Balok Kategori Desain Seismik D”(Jurnal) Gorontalo : Universitas Negeri Gorontalo

Rohmad Abdoel dkk. 2017 “Perencanaan Struktur Gedung Rumah Sakit Islam Gigi Dan Mulut Rsi Sultan Agung Semarang"(Jurnal)Semarang : Universitas Diponegoro.

Syahidah, Faizah. 2017. "Studi Perbandingan Desain Struktur Menggunakan Sistem Rangka Gedung dengan Sistem Ganda Sesuai SNI 1726:2012 dan SNI 2847:2013 “. Surabaya : Institut Teknologi Sepuluh November

Wibowo Prihatmoko Amdhani,2012"Perencanaan Struktur Gedung Beton Bertulang dengan SRPMK dan SRPMM" (Skripsi)Yogyakarta:Universitas Negeri Yogyakarta 